\title{
On the possibilities and considerations of interfacing ultra-high vacuum equipment with an electrochemical setup
}

Maagaard, Thomas; Tiwari, Aarti; Chorkendorff, lb; Horch, Sebastian

Published in:

ChemPhysChem

Link to article, DOI:

$10.1002 /$ cphc. 201900588

Publication date:

2019

Document Version

Peer reviewed version

Link back to DTU Orbit

Citation (APA):

Maagaard, T., Tiwari, A., Chorkendorff, I., \& Horch, S. (2019). On the possibilities and considerations of interfacing ultra-high vacuum equipment with an electrochemical setup. ChemPhysChem, 20(22), 3024-3029. https://doi.org/10.1002/cphc.201900588

\section{General rights}

Copyright and moral rights for the publications made accessible in the public portal are retained by the authors and/or other copyright owners and it is a condition of accessing publications that users recognise and abide by the legal requirements associated with these rights.

- Users may download and print one copy of any publication from the public portal for the purpose of private study or research.

- You may not further distribute the material or use it for any profit-making activity or commercial gain

- You may freely distribute the URL identifying the publication in the public portal 


\title{
On the possibilities and considerations of interfacing ultra-high vacuum equipment with an electrochemical setup
}

\author{
Dr. Thomas Maagaard* Dr. Aarti Tiwari* Prof. Dr. Ib Chorkendorff* \\ Prof. Dr. Sebastian Horch*†
}

August 23, 2019

\section{Abstract}

Efficient electrocatalysts are required in order for electrocatalysis to play a large role in a future largely based on renewable energy sources. To rationally design these catalysts we need to understand the fundamental origin of their activities. In order to elucidate the relationship between catalyst structure and electrochemical behaviour, we investigate well-defined single-crystal catalysts in a UHV chamber interfaced with an electrochemical setup. Using the capabilities of UHV based methods, we can prepare more complex surface structures than it is possible with traditional EC methods and investigate their electrochemical behaviour. We exemplify this by showing results from both clean and intentionally structured $\mathrm{Pt}(111), \mathrm{Cu}(111)$ and $\mathrm{Pt} / \mathrm{Cu}(111)$.

\section{Introduction}

To enable the transition to an energy infrastructure based largely on intermittent energy sources such as wind and sun there is a need for efficient ways of either storing excess energy or using it in the production of important chemicals. Electrocatalysis aims to solve part of this challenge by providing means of storing electrical energy in chemical bonds like $\mathrm{H}_{2}$ or by converting e.g. $\mathrm{CO}_{2}$ to useful chemicals.[1, 2]

*SurfCat, DTU Physics, The Technical University of Denmark, 2800 Kgs. Lyngby, Denmark

${ }^{\dagger}$ Corresponding author
Experiments in fundamental catalysis research on well-defined model systems have traditionally been carried out in the safe confines of ultra-high vacuum (UHV) chambers. Firstly, because it allows for studying the catalyst in question at its cleanest state before it is exposed to the reaction environment. Secondly, because a lot of catalysis until now has been within the realms of heterogeneous catalysis utilising reactants in the gas phase. Regarding the latter point it is easy to see why it makes sense to extend systems already capable of handling vacuum and clean gases with reaction chambers where a given catalytic reaction can take place. This circumvents a sample transfer through ambient air. The fact that reactants are in the gas phase means reactions can be run at a range of different pressures making it possible to bridge the gap between the UHV chambers and catalysts under industrial working conditions involving pressures of up to many bars.[3]

Similarly, there is a long tradition of coupling electrochemical (EC) measurements with UHV systems using transfer systems.[4-8] One reason was to be able to investigate the nature of the EC system with the possibilities offered by UHV based spectroscopies. When trying to identify active sites on a catalyst, preparation and characterization of well-defined surfaces in UHV turned out to be necessary.[9] This has especially become true as the electrocatalytic materials have become more and more complex in nature and it has become increasingly challenging to elucidate the exact state of the catalytically active surface under reaction conditions. This is due to the fact that 
most EC experiments are carried out in a completely separate setup to where the catalysts themselves were prepared. As opposed to gas phase catalysis, electrocatalytic experiments often utilise liquid electrolytes which require ambient conditions.

Thus in order to get closer to understanding the electrochemically active sites of a catalyst and by extension the catalytically active sites we need to be as sure as possible what a given electrocatalyst looks like upon immersion into the EC environment. That means performing in situ[10, 11] and operando[12] measurements where possible and avoiding sample transfer through ambient air before measuring[13]. The latter can be achieved by interfacing a UHV chamber with an EC setup. This then also opens up for some novel possibilities for the preparation of the catalyst's surface that are not possible with traditional electrochemical preparation methods thus making it easier to correlate surface sites with e.g. catalytic activity. UHV experiments often go hand in hand with model systems such as single-crystals which also makes it easier to compare results to theory. Finally, the result of certain EC techniques like under potential deposition (UPD) can be understood much easier by the characterisation tools available in the UHV chamber.

In the present paper, we will first exemplify this concept by investigating the influence of increased step density, visualised by scanning tunneling microscopy (STM), on the EC behaviour of two different single-crystal electrodes. As systems we have chosen $\mathrm{Pt}(111)$ in $0.1 \mathrm{M} \mathrm{HClO}_{4}$ and $\mathrm{Cu}(111)$ in $0.1 \mathrm{M} \mathrm{KOH}$. The former was measured to validate the trustworthiness of our setup as $\mathrm{Pt}(111)$ is one of the most studied electrocatalyst. $\mathrm{Cu}(111)$ was chosen as a sample due to $\mathrm{Cu}$ being the only pure metal electrocatalyst which can catalyse the reduction of $\mathrm{CO}_{2}$ to a range of different interesting products with a reasonable faradaic efficiency.[14] Furthermore, the fundamental EC properties of $\mathrm{Cu}$ are still under debate.[15] The electrolytes were picked as they are prevalent in the literature for these sample types. As a second example, we look at a UHV prepared bimetallic $\mathrm{Pt} / \mathrm{Cu}(111)$ system with a complex structure.

\section{Description of the Experi- mental Setup}

\subsection{UHV chamber and add-on com- partment}

The main UHV chamber is a conventional one made of stainless steel. It is equipped with an Aarhus type STM[16, 17], an argon sputter gun, a stage that allows for heating of the sample, a quartz crystal microbalance (QCM), a metal evaporator for physical vapour deposition (PVD), a mass spectrometer, leak valves for letting in e.g. $\mathrm{O}_{2}$, and an Auger electron spectroscopy system. The chamber is mainly pumped by a magnetically suspended turbopump (Pfeiffer) with a reasonably low noise level so it can be left running during STM imaging and EC measurements. Additionally, an ion pump is available and we routinely reach a base pressure of $1 \times 10^{-11}$ mbar as measured using an inverted-magnetron gauge (Agilent IMG-300).

A home-built add-on system consisting of a magnetic transfer arm (Ferrovac) with a $4.5^{\prime \prime}$ spherical cube vacuum chamber (Kimball Physics) placed midway on it is connected to the main chamber (c.f. Figures S1, S2 and S3 in the supporting information). This cube will henceforth be referred to as the $E C$ cube. Using the transfer arm, the sample can be moved from the main UHV chamber into the cube under UHV conditions. A 3-axis manipulator attached to the cube is used to move a sample container similar to the one in the main UHV chamber. This container receives the sample from the transfer arm. Before electrochemical measurements the cube is sealed off from the main UHV chamber and is solely pumped by a small turbo pump (Pfeiffer). When the sample is in the container in the cube, the cube is vented to proceed with the measurement. To this end, a gas line is connected directly to the cube to facilitate the introduction of inert gases to sustain a mild overpressure during the measurements, thus preventing back-flow of oxygen through the opening by which the EC cell is introduced. The typical base pressure of the entire add-on system is $\sim 10^{-8}$ mbar when pumped by the small turbo pump only. In principle, the system 
can be further baked over night to remove remaining water condensed on the walls, resulting in a base pressure below $10^{-9}$ mbar. In practice, however, we prefer a rapid measuring cycle and aim for one experiment per day and thus do not bake the system on a daily basis.

\subsection{EC setup}

The EC cell is designed to form a hanging meniscus geometry within the spatial constraints of the EC cube. The cell itself is cylindrical allowing for controlled contact to the circular single-crystal samples, and is machined from a single piece of Kel-F with an electrolyte volume of $\sim 0.22 \mathrm{~mL}$. Three threaded ports in the cell makes it possible to fasten tubes acting as inlet and outlet as well as a counter electrode (CE) (the cell is shown in Figures S5, S6 and S8b). The reference electrode $(\mathrm{RE})$ is placed downstream in the outlet. The cylindrical electrolyte volume consists of two channels, a narrow and a wide one. The narrow one acts as outlet whereas the wide one contains the inlet and the $\mathrm{CE}$. The reason for this is to make it possible to compensate for the ohmic resistance of the system properly as that cannot be done with the $\mathrm{CE}$ and RE in the same channel. For the measurements shown here, the tubes were $1 / 8^{\prime \prime} \mathrm{PFA}$ tubes (IDEX Health \& Science), the CE was a Pt wire $\left(0.5 \mathrm{~mm}\right.$ diameter, $\sim 30 \mathrm{~mm}^{2}$ geometric surface area, $99.99 \%$, Chempur) (c.f. Figure S8a), the RE was a calibrated RHE (c.f. Figure S7). Finally, an auxiliary working electrode (AWE) of the same material as the sample can be employed if needed.

Electrolyte is simply fed to the EC cell in the EC cube by elevating a PFA supply bottle (Savillex) above the position of the cell and afterwards opening a stopcock connecting it to the inlet tube (c.f. Figures S4 and S9).

Prior to EC measurements, the EC cell and electrolyte supply bottle were boiled several times in millipore water (18.2 M $\Omega \mathrm{cm}$, Merck Millipore). Furthermore, the $\mathrm{CE}$ was cycled between 0 and $1.6 \mathrm{~V}$ vs. RHE until a stable CV was obtained. The AWE was also cycled electrochemically until stable between the hydrogen evolution potential and the oxygen evolution potential. Additionally the inlet tube was first rinsed with warm millipore water and then the electrolyte to get rid of the remaining millipore. A BioLogic SP200 and the accompanying EC-Lab software was used to conduct the EC measurements. The electrolytes were made from millipore water and $\mathrm{HClO}_{4}$ (70\% redistilled, 99.999, Sigma-Aldrich) and $\mathrm{KOH}$ (99.995 Suprapur, Merck), respectively. The samples were from MaTeck, Jülich with a purity of $99.9999 \%$.

The Supporting Information contains an elaborate description of a typical experiment.

\section{Results and Discussion}

\subsection{Clean surfaces and electrochemi- cal benchmarks}

The most basic experiment one can think of using a setup combining UHV prepared samples and EC measurements consists of preparing well-defined samples, i.e. as flat and clean as possible and measuring them in blank electrolytes.

Flat, clean single crystal samples can easily be obtained in UHV by cycles of Ar sputtering and annealing. The cleanliness and uniformity of the samples was routinely investigated with STM prior to EC measurements. Figure 1a shows an STM image of the as prepared Pt(111) surface. As can be seen the surface is made up of large clean terraces separated by monoatomic-high steps. Cleanliness of the samples was occasionally verified with AES or XPS both prior to or after EC measurements. The CV measured in $0.1 \mathrm{M}$ deaerated $\mathrm{HClO}_{4}$ between 0.05 and $0.9 \mathrm{~V}$ vs. RHE on such a sample is shown in Figure $1 \mathrm{~b}$ and is consistent with those shown in the literature.[18]

Likewise a $\mathrm{Cu}(111)$ single crystal can be prepared using the same techniques. Figure 2a shows the STM image of a clean $\mathrm{Cu}(111)$ surface, again featuring large terraces and monoatomic-high steps. The sample when measured electrochemically, this time in $0.1 \mathrm{M}$ deaerated $\mathrm{KOH}$ between -0.2 and $0.45 \mathrm{~V}$ vs. RHE, gives rise to the $\mathrm{CV}$ shown in Figure $2 \mathrm{~b}$. We recently proposed this $\mathrm{CV}$ as the benchmark for $\mathrm{Cu}(111)$ in $0.1 \mathrm{M} \mathrm{KOH}$ (and $\mathrm{NaOH}$ ) in the absence of dissolved glassware.[19] 

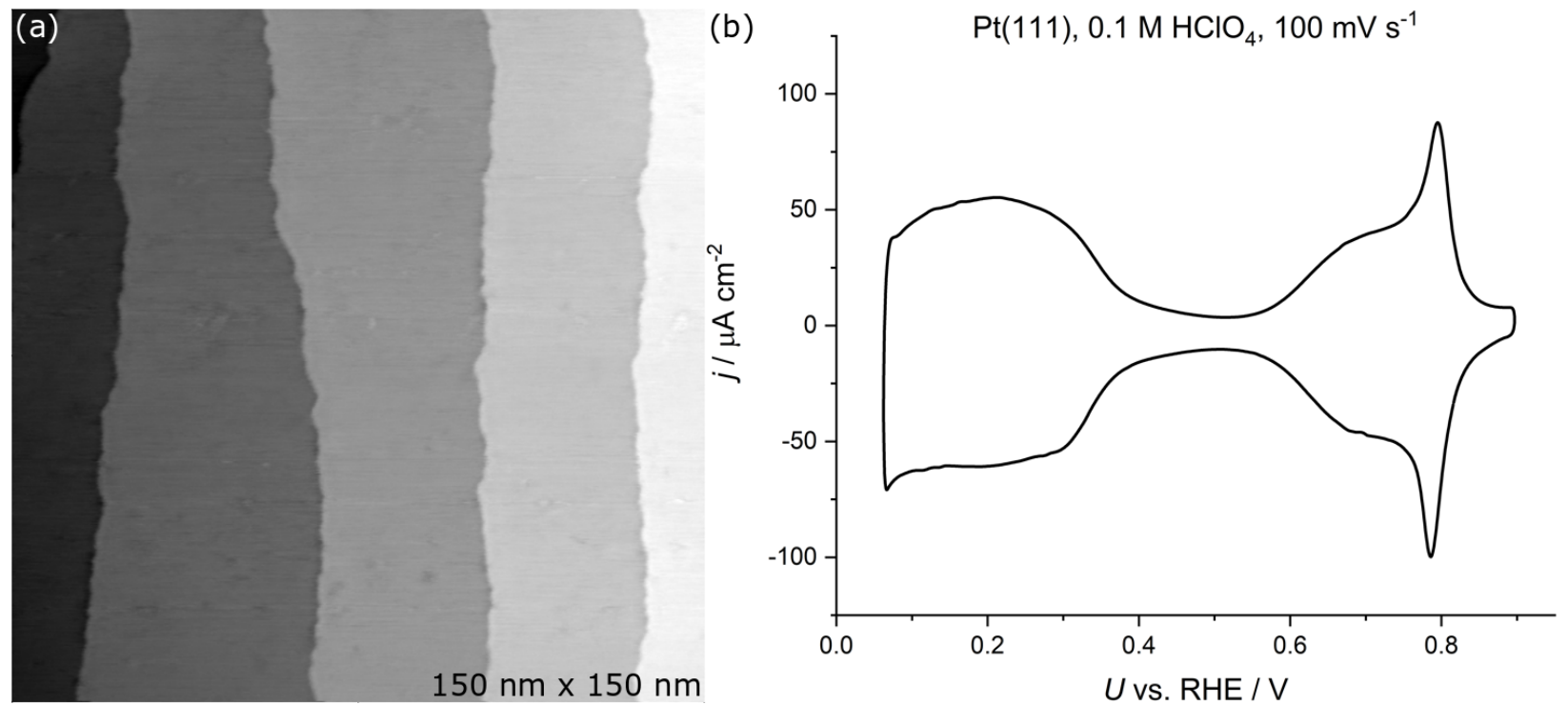

Figure 1: (a) $150 \mathrm{~nm} \times 150 \mathrm{~nm}$ STM image of a Pt(111) surface prepared by cycles of Ar sputtering and annealing. (b) Corresponding CV measured from 0.06 to $0.9 \mathrm{~V}$ vs. RHE.

\subsection{Step-rich surfaces}

As mentioned, UHV makes it possible to prepare samples with a range of well-defined surface morphologies, even surfaces that cannot be prepared by traditional EC preparation. Combined with the EC setup the effect of various surface structures on the resulting $\mathrm{CV}$ can be investigated.

By tuning the sputter and annealing procedure, it is possible to prepare surfaces with well-defined multi-layer deep hexagonal vacancy islands or, seen in another way, with a larger amount of steps running in high symmetry directions.[20, 21] The steps run in both high symmetry directions which is qualitatively different from the traditionally used vicinal surfaces used in e.g. Feliu's work that present only one prevailing step direction.[22, 23] Figure 3a shows a $\mathrm{Pt}(111)$ surface prepared with a higher step density than the clean sample shown previously. This changes the electrochemical response as can be seen in Figure 3b compared to Figure 1b. Two new features appear in the cathodic sweep of the hydrogen $\mathrm{UPD}$ region, one at $0.09 \mathrm{~V}$ vs. $\mathrm{RHE}$ and one at $0.13 \mathrm{~V}$ vs. RHE. The former of which also has an anodic equivalent, although at $0.14 \mathrm{~V}$ vs. RHE. However, as can be seen, there is a clear peak separation of the butterfly feature around $0.8 \mathrm{~V}$ vs. RHE due to issues with the ohmic compensation during this experiment. This can be traced back to using an EC cell with only one inner channel. Had we had a two channel EC cell at this point in time we would have observed the features in the cathodic scan slightly more positive and vice versa meaning the redox feature at the lowest potential would be closer to $0.13 \mathrm{~V}$ vs. RHE, which was also shown by Gómez-Marín and Feliu on a Pt(554) surface.[23] This suggests that we have indeed formed a surface with higher density of $\{111\}$-steps. There is also a hint of a feature around $0.28 \mathrm{~V}$ vs. RHE from $\{100\}$-steps (mostly seen in the anodic scan). Finally, Figure 3c shows the sample after $70 \mathrm{EC}$ cycles between 0.05 and $1.0 \mathrm{~V}$ vs. RHE. The surface was imaged directly after emersion from the electrolyte and has not changed much during the EC measurements as evident from the still visible hexagonal vacancy islands. The only artefact 

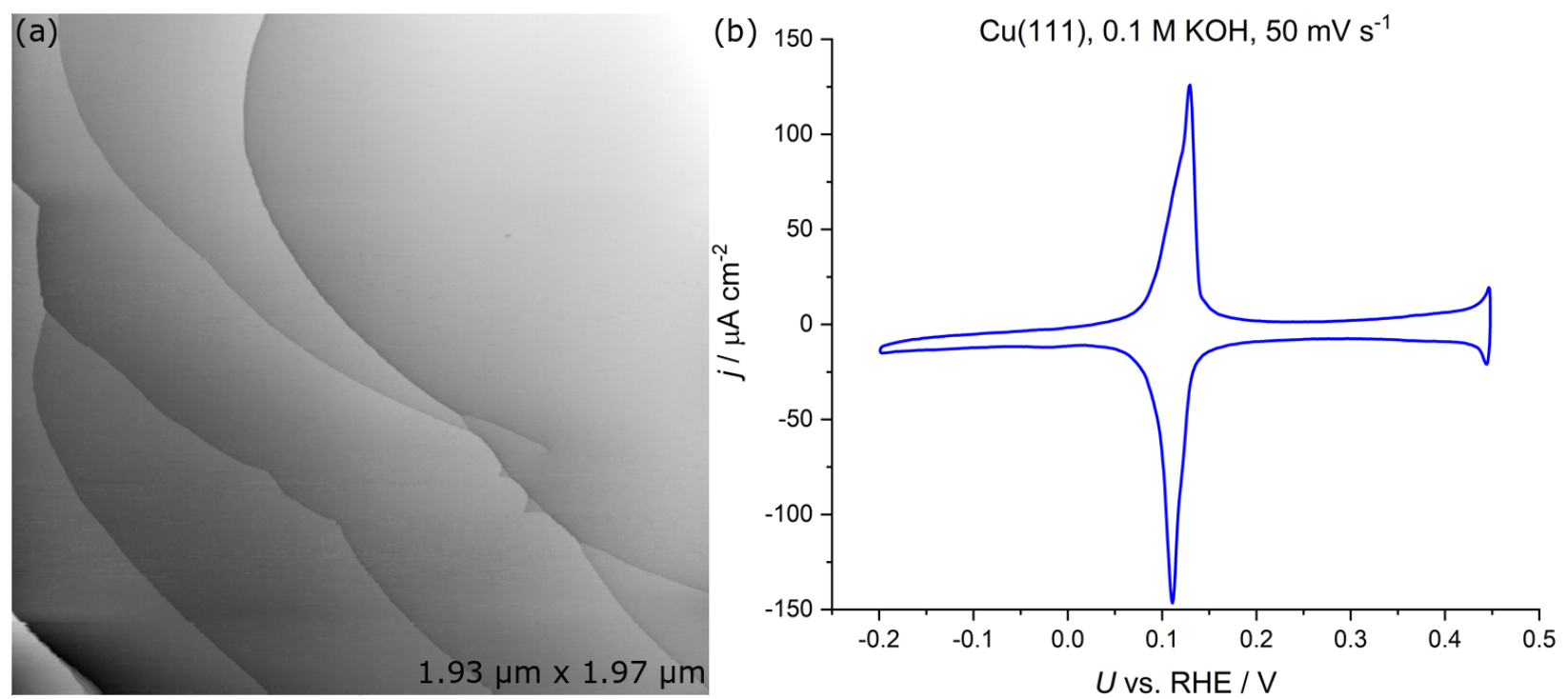

Figure 2: (a) $1.93 \mu \mathrm{m} \times 1.97 \mu \mathrm{m}$ STM image of the clean $\mathrm{Cu}(111)$ sample after Ar sputtering and annealing. (b) Corresponding $\mathrm{CV}$ in $0.1 \mathrm{M} \mathrm{KOH}$ measured at $50 \mathrm{mV} / \mathrm{s}$ from -0.2 to $0.45 \mathrm{~V}$ vs. RHE

left from the excursion into and out of the EC environment is something resembling "film-grain" on the surface, most likely due to remaining electrolyte which could not be removed prior to transferring the sample back to the main UHV chamber.

If we perform a similar preparation with $\mathrm{Cu}(111)$ and prepare a step-rich surface through sputtering and annealing, we obtain samples like the one shown in Figure 4a. Due to the higher self-diffusion rate of $\mathrm{Cu}$, the multi-layer deep holes rapidly anneal and leave the surface with much larger 1-2 layer deep holes. The corresponding $\mathrm{CV}$ is shown in Figure $4 \mathrm{~b}$. This time we hardly observe a change in the CV compared to Figure 2b suggesting that the feature we see at $0.11 \mathrm{~V}$ vs. RHE is mainly associated with terrace sites.

\subsection{Deposited adislands}

One big advantage provided by a UHV system is that it is much easier to deposit various materials on top of each other, e.g. by physical vapour deposition (PVD). Furthermore, by adjusting the deposi- tion parameters like rate and temperature, it is often possible not only to deposit a well-defined amount of material, but also to define where the material should deposit or what structure it should have. In that way one can e.g. investigate the stability of adislands or changes in their shape resulting from EC measurements. Furthermore, by depositing a metal different from the substrate, interface effects, alloys or singleatom catalytic centers can be investigated.[24-26]

As an example, we investigated the change in the $\mathrm{Cu}(111) \mathrm{CV}$ due to deposition of small amounts of Pt onto the sample. Figure 5a shows an STM image of $\sim 10 \%$ of a monolayer of $\mathrm{Pt}$ deposited in the form of small nanoparticles on $\mathrm{Cu}(111)$. To obtain these nanoparticles, we intentionally oxidised the $\mathrm{Cu}(111)$ sample lightly and deposited the Pt using PVD in UHV. The deposition rate was $0.005 \AA / \mathrm{s}$ at $319 \mathrm{~K}$. Using this preparation, we were able to deposit $\mathrm{Pt}$ as small separate clusters instead of big islands. The resulting nanoparticles have a mean diameter of $\sim 1.2 \mathrm{~nm}$. As can be seen in the $\mathrm{CV}$ in Figure $5 b$, the main feature of $\mathrm{Cu}(111)$ is still present at $0.11 \mathrm{~V}$ vs. RHE but is relatively less intense com- 
pared to the $\mathrm{CV}$ in Figure 2b. This could be due to the fact the $\mathrm{Pt}$ adislands are covering a certain amount of terrace sites. Furthermore, the onset of HER is more positive than observed previously, as expected. Measurements like these can, in principle, be performed for any amount of deposited material and are not restricted to special coverages like in the case of UPD.

\section{Conclusions}

We have presented some initial results that show promising opportunities to help elucidate some otherwise difficult to investigate systems - either because they are difficult to prepare in the EC environment or because it is difficult to quantify their state, e.g. geometry before and after EC. $\mathrm{Cu}(111)$, as an example, was only possible to benchmark and be confident of due to the STM data showing that the sample was in fact clean prior to the EC measurement. Likewise, we could check the result and uniformity of a preparation procedure, like the deposited adislands, before measuring the EC behaviour.

The main drawback of the current setup is clearly the limited possibility for product detection and analysis, where a combination with DEMS and/or a sniffer chip[27] would greatly enhance the possibilities.

One can also imagine the possibility of performing e.g. $\mathrm{Pb}$ UPD and afterwards use STM to investigate on which sites the $\mathrm{Pb}$ atoms ended up being deposited.

\section{Acknowledgement}

This work was supported by research grant 9455 from VILLUM FONDEN and the European Union's Horizon 2020 research and innovation programme under the Marie Sklodowska-Curie grant agreement no. 713683 .

\section{$7 \quad$ Keywords}

Electrochemistry, scanning probe microscopy, single crystals, surface science, UHV

\section{References}

[1] Z. W. Seh, J. Kibsgaard, C. F. Dickens, I. Chorkendorff, J. K. Nørskov, T. F. Jaramillo, Science 2017, 355, eaad4998.

[2] S. Nitopi, E. Bertheussen, S. B. Scott, X. Liu, A. K. Engstfeld, S. Horch, B. Seger, I. E. L. Stephens, K. Chan, C. Hahn, J. K. Nørskov, T. F. Jaramillo, I. Chorkendorff, Chem. Rev. 2019, acs.chemrev.8b00705.

[3] R. Imbihl, R. J. Behm, R. Schlögl, Phys. Chem. Chem. Phys. 2007, 9, 3459.

[4] W. Hansen, D. Kolb, D. Rath, R. Wille, J. Electroanal. Chem. Interfacial Electrochem. 1980, 110, 369-373.

[5] A. Hubbard, J. Stickney, M. Soriaga, V. Chia, S. Rosasco, B. Schardt, T. Solomun, D. Song, J. White, A. Wieckohski, J. Electroanal. Chem. Interfacial Electrochem. 1984, 168, 43-66.

[6] D. Aberdam, R. Durand, R. Faure, F. El-Omar, Surf. Sci. 1986, 171, 303-330.

[7] C. Stuhlmann, B. Wohlmann, Z. Park, M. Kruft, P. Broekmann, K. Wandelt in Solid-Liquid Interfaces, Vol. 223, 111, Springer Berlin Heidelberg, Berlin, Heidelberg, 2007, pp. 199-223.

[8] M. P. Mercer, H. E. Hoster, Nano Energy 2016 29, 394-413.

[9] T. F. Jaramillo, K. P. Jorgensen, J. Bonde, J. H. Nielsen, S. Horch, I. Chorkendorff, Science 2007, 317, 100-102.

[10] O. Magnussen, K. Krug, A. Ayyad, J. Stettner, Electrochim. Acta 2008, 53, 3449-3458.

[11] D. Friebel, D. J. Miller, C. P. O'Grady, T. Anniyev, J. Bargar, U. Bergmann, H. Ogasawara, K. T. Wikfeldt, L. G. M. Pettersson, A. Nilsson, Phys. Chem. Chem. Phys. 2011, 13, 262266. 
[12] S. B. Scott, T. V. Hogg, A. T. Landers, T. Maagaard, E. Bertheussen, J. C. Lin, R. C. Davis, J. W. Beeman, D. Higgins, W. S. Drisdell, C. Hahn, A. Mehta, B. Seger, T. F. Jaramillo, I. Chorkendorff, ACS Energy Lett. 2019, 4, 803804.

[13] M. El-Jawad, J.-L. Chemin, B. Gilles, F. Maillard, Rev. Sci. Instrum. 2013, 84, 064101.

[14] Y. Hori in Modern Aspects of Electrochemistry, Vol. 42, (Eds.: C. Vayenas, R. White, M. Gamboa-Aldeco), Springer, 2008, Chapter 3, pp. 89-189.

[15] A. K. Engstfeld, T. Maagaard, S. Horch, I. Chorkendorff, I. E. L. Stephens, Chem. - Eur. J. 2018, 24, 17743-17755.

[16] E. Laegsgaard, F. Besenbacher, K. Mortensen, I. Stensgaard, J. Microsc. 1988, 152, 663-669.

[17] F. Besenbacher, E. Laegsgaard, K. Mortensen, U. Nielsen, I. Stensgaard, Rev. Sci. Instrum. 1988, 59, 1035-1038.

[18] V. Climent, J. M. Feliu, J. Solid State Electr. 2011, 15, 1297-1315.

[19] A. Tiwari, T. Maagaard, I. Chorkendorff, S. Horch, ACS Energy Lett. 2019, 4, 1645-1649.

[20] T. Michely, G. Comsa, Surf. Sci. Lett. 1991, 256, A537.

[21] T. Michely, M. Hohage, M. Bott, G. Comsa, Phys. Rev. Lett. 1993, 70, 3943-3946.

[22] A. Björling, E. Herrero, J. M. Feliu, J. Phys. Chem. C 2011, 115, 15509-15515.

[23] A. M. Gómez-Marín, J. M. Feliu, Electrochim. Acta 2012, 82, 558-569.

[24] A. Engstfeld, J. Klein, S. Brimaud, R. Behm, Surf. Sci. 2015, 631, 248-257.

[25] A. K. Engstfeld, S. Brimaud, R. J. Behm, Angew. Chem. Int. Edit.) 2014, 53, 12936-40.

[26] F. Faisal, M. Bertram, C. Stumm, F. Waidhas, O. Brummel, J. Libuda, Rev. Sci. Instrum. 2018, 89, 114101.
[27] D. B. Trimarco, S. B. Scott, A. H. Thilsted, J. Y. Pan, T. Pedersen, O. Hansen, I. Chorkendorff, P. C. Vesborg, Electrochim. Acta 2018, 268, 520-530. 


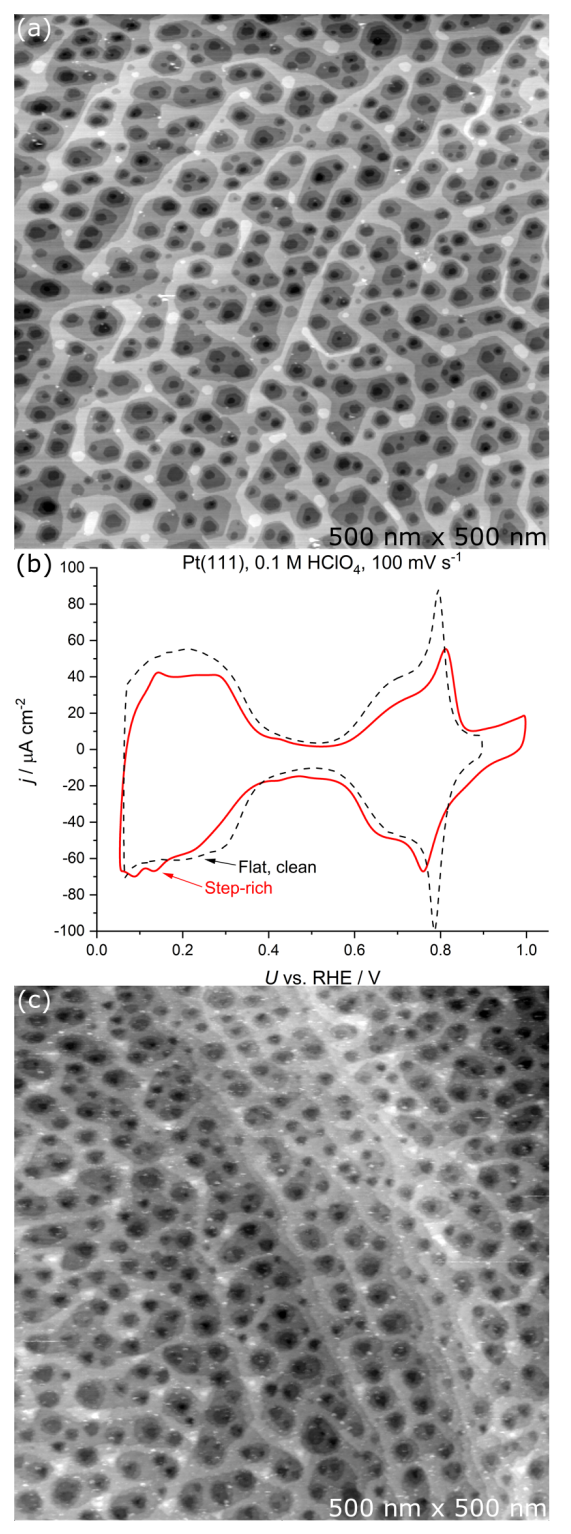

Figure 3: (a) $500 \mathrm{~nm} \times 500 \mathrm{~nm}$ STM image of a steprich $\mathrm{Pt}(111)$ sample prepared using Ar sputtering and annealing. (b) The CV obtained in $0.1 \mathrm{M} \mathrm{HClO}_{4}$ at $100 \mathrm{mV} / \mathrm{s}$. Note the new features in the H-UPD region compared to Fig. 1b. (c) $500 \mathrm{~nm} \times 500 \mathrm{~nm}$ STM image of the surface emersed from electrolyte after 70 cycles from 0.05 to $1.0 \mathrm{~V}$ vs. RHE. 

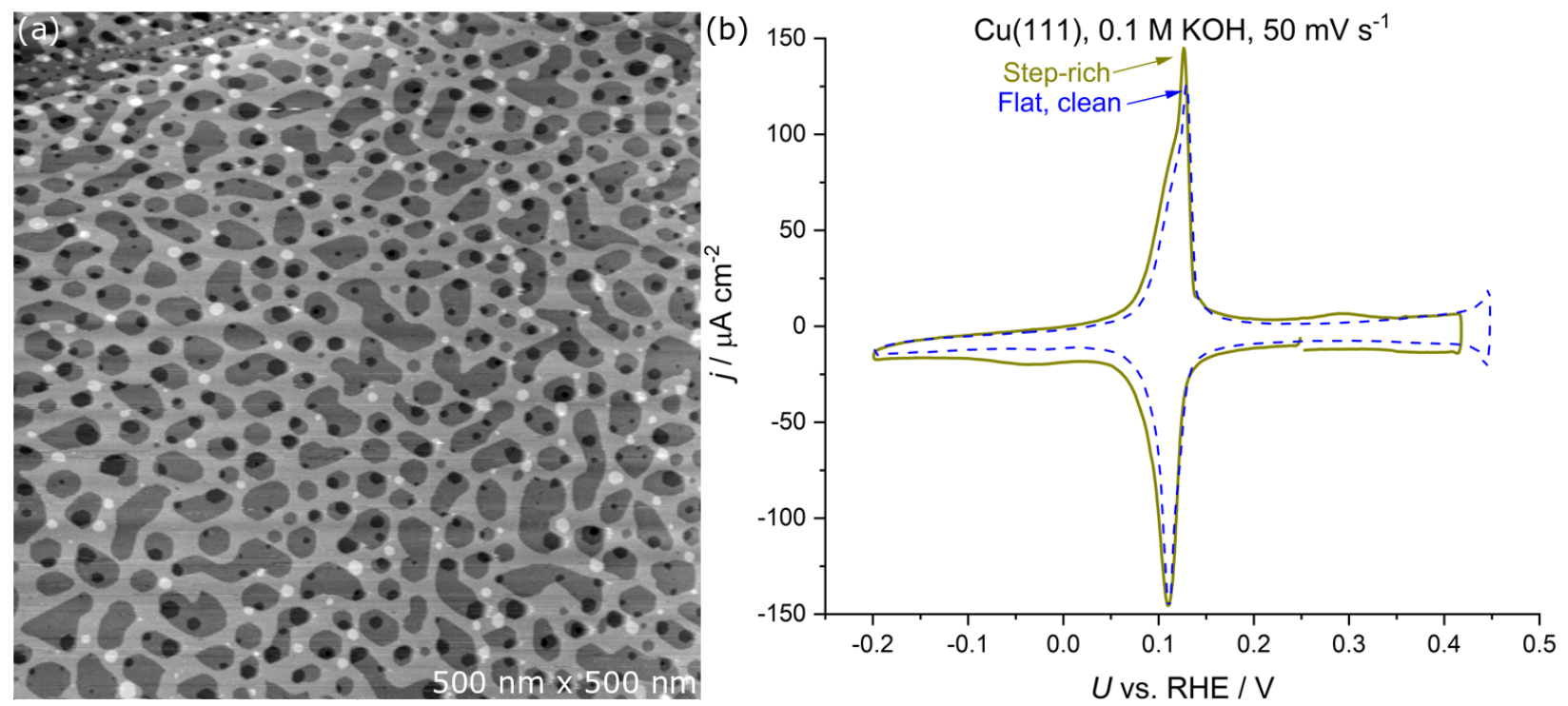

Figure 4: (a) $500 \mathrm{~nm} \times 500 \mathrm{~nm}$ STM image of a step-rich $\mathrm{Cu}(111)$ sample. (b) The CV measured in $0.1 \mathrm{M}$ $\mathrm{KOH}$. This time it closely resembles the CV shown in Fig. 2b.
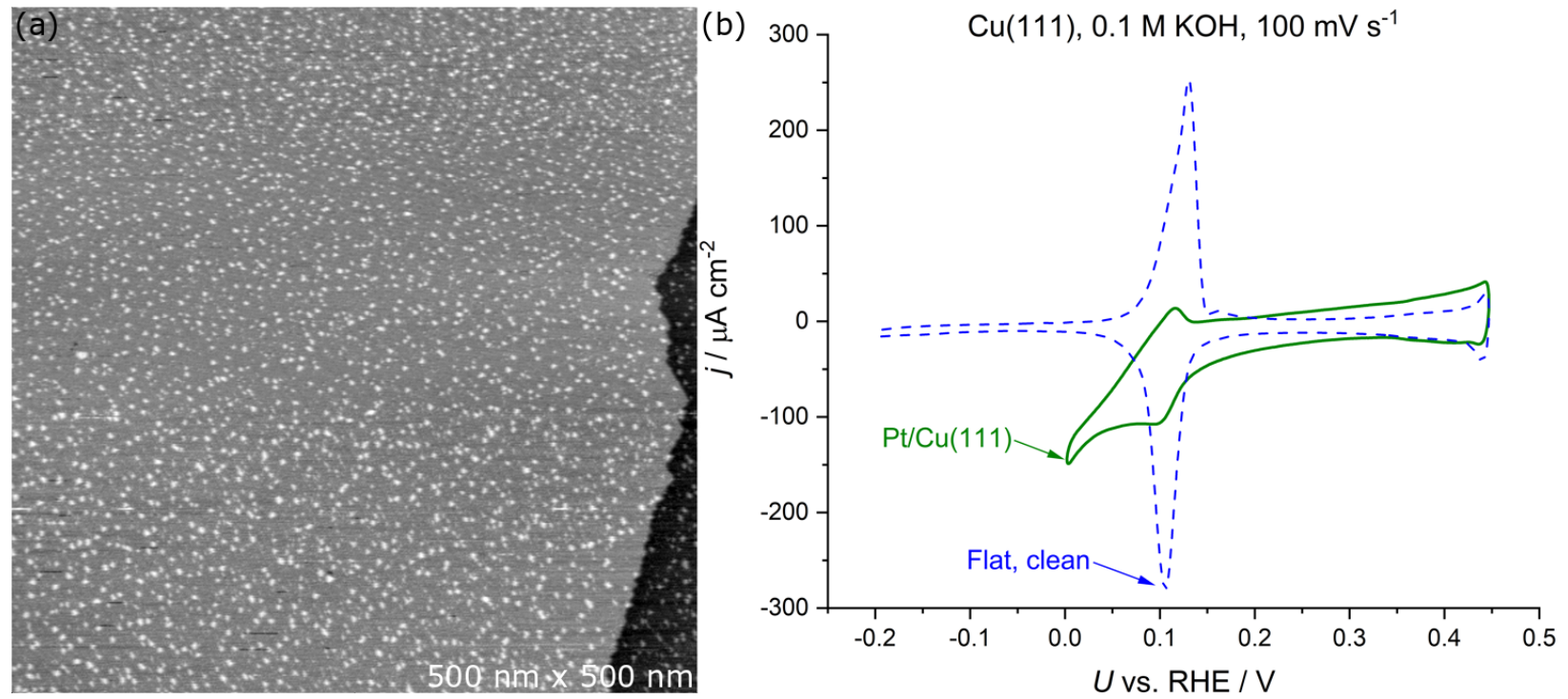

Figure 5: (a) $500 \mathrm{~nm} \times 500 \mathrm{~nm}$ STM image of a $\mathrm{Cu}(111)$ sample with $\sim 10 \%$ of a monolayer of Pt deposited using PVD. The Pt nanoparticles have a diameter of $\sim 1.2 \mathrm{~nm}$. (b) A CV of this system in $0.1 \mathrm{M} \mathrm{KOH}$. As expected HER has a more positive onset potential. The redox feature at $0.11 \mathrm{~V}$ vs. RHE is also much less intense compared to Fig. 2b. Note the scan rate was $100 \mathrm{mV} / \mathrm{s}$. 


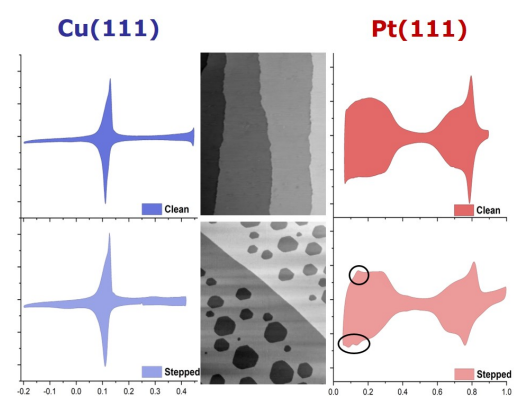

Figure 6: TOC text: UHV based techniques allow for the preparation of well-defined samples which in turn provides a foundation for a better understanding of electrochemical behaviour of the given material. As examples of this we show how the influence of step- and terrace sites on the blank voltammetry of Pt(111) and $\mathrm{Cu}(111)$ differ from one another. Tools like this can be used as a way to establish electrochemical benchmarks of various samples. 